\title{
Influence of hydrogen on chemical vapour synthesis of different carbon nanostructures using propane as precursor and nickel as catalyst
}

\author{
R K SAHOO $^{1}$, H MAMGAIN ${ }^{2}$ and C JACOB ${ }^{1, *}$ \\ ${ }^{1}$ Materials Science Centre, Indian Institute of Technology, Kharagpur 721 302, India \\ ${ }^{2}$ WITec GmbH, Lise-Meitner Strasse 6, D-89081 Ulm, Germany
}

MS received 13 June 2013; revised 16 August 2013

\begin{abstract}
The role of hydrogen in the catalytic chemical vapour deposition of carbon nanotubes using sputtered nickel thin film as a catalyst is explained in this work. The growth of different carbon nanostructures with the variation in the precursor gas content was studied by keeping all other process parameters constant and using sputtered $\mathrm{Ni}$ thin film as a catalyst. The catalyst granule size, its external morphology and the resulting products were analysed. Carbon nanotubes (CNTs), carbon nanofibres (CNFs) and carbon nanoribbons (CNRs) were observed under different growth conditions. The different conditions of growth leading to form tubes, fibres or ribbons were analysed by varying the flow ratio of propane and hydrogen gas during the high temperature growth. Scanning and transmission electron microscopies confirmed the above structures under different growth conditions. The role of hydrogen on the surface passivation behaviour of the Ni catalyst and its correlative effect on the growth of carbon nanostructures is analysed. This direct approach can, in principle, be used to synthesize different types of carbon nanostructures by tailoring the hydrogen concentration.
\end{abstract}

Keywords. Carbon nanotube growth; carbon nanoribbon; atomic hydrogen; atmospheric chemical vapour deposition.

\section{Introduction}

Chemical vapour deposition (CVD) is one of the promising and controlled synthesis methods for the growth of carbon nanomaterials. In the CVD process, the growth of carbon nanomaterials is usually carried out using metal particles as the catalyst. There are many reports on the growth using different transition metal catalysts like $\mathrm{Fe}, \mathrm{Ni}, \mathrm{Co}$, $\mathrm{Mo}, \mathrm{Au}, \mathrm{Ag}, \mathrm{Zn}, \mathrm{Al}$, metallic alloys and non-metallic catalysts like $\mathrm{SiO}_{2}, \mathrm{Al}_{2} \mathrm{O}_{3}$, etc (Yuan et al 2008; Huang et al 2009; Hong et al 2012) as well as metal-free growth of nitrogen-doped CNTs (Yu et al 2010). For better control of the process parameters and to develop an understanding of the growth, researchers have used variations in the precursor gas (Nessim et al 2011), adding extra diluting gas with the precursor (Crossley et al 2010) and growthpromoting and enhancing agents (Ren et al 2006). However, precise control of the growth parameters for the growth of carbon nanomaterials still remains elusive because the growth mechanism and the reaction kinetics are not fully clear.

There are also several reports on the growth mechanism, kinetics, catalyst size variation and mass production of

\footnotetext{
*Author for correspondence (cxj14_holiday@yahoo.com)
}

carbon nanostructures using $\mathrm{Ni}$ as a catalyst (Bianchini and Lund 1989; Jablonski and Sacco 1992; Snoeck et al 1997; Benito et al 1998; Ren et al 2006). From the literature, it is known that the growth of carbon nanostructures is suppressed by the passivation of the nickel surface. There are two reasons for surface passivation: (a) at low temperatures, polymeric encapsulation and (b) at high temperatures, the excess decomposition of the hydrocarbon (Bartholomew 1982; Jung et al 2001). An increase in the hydrogen concentration and a decrease in the hydrocarbon concentration prevent passivation, resulting in carbon nanofibre (CNF) growth (Chen et al 2006; Pollard et al 2009; Kato and Hatakeyama 2012). Thus, the variation of hydrogen concentration in the system can influence the growth of CNTs, CNFs or CNRs by affecting the passivation of oxide.

It has been identified and reported in the literature that hydrogen treatment is one of the critical components in the catalytic growth of carbon nanofibres (Park and Keane 2001a,b, 2002; Baker 1989; Huang et al 2002; Cherukuri et al 2004). Hydrogen also has an influence on the graphitic nature of the grown CNFs (Park and Keane 2004). Huang et al (2002) reported that the prolonged treatment of the catalyst in hydrogen resulted in smoother and longer fibres. 
Additionally, in the recent past, several groups have reported the growth of flat two-dimensional carbon nanostructures, like carbon nanoribbons and graphene, using $\mathrm{Ni}$ as a catalyst ( $\mathrm{Yu}$ et al 2008; Chae et al 2009; Kato and Hatakeyama 2012; Umair and Raza 2012). However, there are very few reports on the role of hydrogen, which is one of the important parameters in the formation of carbon nanoribbon using $\mathrm{Ni}$ as a catalyst. Recently, Wang et al (2013) reported the growth of carbon nanoribbons on the periphery of de-wetted Ni nanoparticles using ethylene $(1 \mathrm{sccm})$ as a precursor gas and a hydrogen:argon $\left(\mathrm{H}_{2}: \mathrm{Ar}=50: 150 \mathrm{sccm}\right)$ mixture as the carrier gas under a low pressure (10 torr). However, this report overlooks the effect of hydrogen in the formation of carbon nanoribbons. Hence, the study of the role of hydrogen in the growth of specific type of carbon nanostructure in atmospheric pressure chemical vapour deposition (APCVD) is of prime importance.

In the present work, carbon nanomaterials were grown from propane by APCVD using sputtered Ni thin films as a catalyst. The growth of CNTs, CNFs and CNRs with the variation in the precursor gas content by mixing with hydrogen was studied keeping all other process parameters constant. The morphologies of the as-grown CNTs, CNFs and CNRs like structures were analysed using field emission scanning electron microscopy. Transmission electron microscopy confirmed the formation of the CNTs, CNFs and CNRs. The quality of the asgrown CNTs, CNFs and CNRs, in terms of their graphitic crystallinity, was analysed by Raman spectroscopy.

\section{Experimental}

\subsection{Growth of thin film}

The Si(100) substrates were ultrasonically cleaned with acetone and deionized water prior to $\mathrm{Ni}$ deposition. The Ni film was deposited by DC sputtering (Korea Vacuum Tech Ltd (KVS-T4065)). The sputter chamber was evacuated to a base pressure lower than $2 \times 10^{-6}$ torr using a turbo molecular pump backed by a rotary pump. A $99.9 \%$ pure Ni target with a diameter of 3" was used. Argon gas of $99.99 \%$ purity was used as the sputtering gas with a constant flow rate of $50 \mathrm{sccm}$. Prior to the Ni deposition, the substrates were etched with $2 \%$ HF solution in order to remove any native oxide layer on the surface. The films were deposited with DC sputtering power of $100 \mathrm{~W}$, deposition pressure 0.01 torr and substrate temperature of $300{ }^{\circ} \mathrm{C}$ for $20 \mathrm{~min}$. $\mathrm{Ni}$ film thickness of $120 \mathrm{~nm}$ was measured by quartz crystal monitor and verified using Veeco-Dektak 150 surface profilometer.

\subsection{Growth of carbon nanostructures}

An APCVD reactor was used for the growth. The Si substrates with the deposited $\mathrm{Ni}$ thin film were loaded onto a hot-wall horizontal reactor having a resistance-heated furnace (ELECTROHEAT EN345T). The reactor consists of a 1.5-m-long quartz tube of $3 \mathrm{~mm}$ wall thickness and $49 \mathrm{~mm}$ outer diameter. The gases used in this reactor are XL grade $\mathrm{Ar}, \mathrm{H}_{2}$ and propane $\left(10 \%\right.$ in $\left.\mathrm{H}_{2}\right)$ supplied by BOC, India. This reactor was pumped down to $10^{-2}$ torr and backfilled with flowing argon to atmospheric pressure. The substrates were then heated in flowing argon $(1000 \mathrm{sccm})$ up to $300{ }^{\circ} \mathrm{C}$. After that, the argon was turned off and the system was heated in hydrogen $(1000 \mathrm{sccm})$ till $900{ }^{\circ} \mathrm{C}$. The temperature was maintained for $10 \mathrm{~min}$ in hydrogen flow and then the reactor was cooled down to the required temperature of growth, i.e. $850{ }^{\circ} \mathrm{C}$. This step is crucial for catalyst preheating for the formation of the nanoparticles on the top of the bigger agglomerated catalyst islands. Finally, the reactor temperature was maintained at the growth temperature, i.e. $850{ }^{\circ} \mathrm{C}$. Thereafter, a propane and hydrogen gas mixture (told flow rate $200 \mathrm{sccm}$ ) were introduced into the gas stream for $30 \mathrm{~min}$ for carbon nanostructure synthesis. The propane-to-hydrogen ratio was maintained at $3: 1,2: 1$, $2: 2$ and $1: 3$ in four separate batches of growth, keeping the flow velocity almost constant. After growth, the propane was turned off and the system was cooled in hydrogen to $300{ }^{\circ} \mathrm{C}$ and below that, in argon, to room temperature.

\subsection{Characterization}

A field emission scanning electron microscope (FESEM) (ZEISS SUPRA 40) and high-resolution transmission electron microscope (HRTEM) (JEOL JEM 2100) equipped with an energy-dispersed X-ray (EDX) analyser (Oxford Instruments) were employed for examination of the morphology and microstructure of the as-grown structures. HRTEM was used to characterize the growth morphology and structure dependence of the nanotubes on the catalysts. The sample preparation for the HRTEM study was done by scraping the grown structures from the $\mathrm{Si}$ substrates and dispersing them ultrasonically in alcohol and transferring to carbon-coated copper grids. Samples were also characterized by a Philips X-ray diffractometer (PW1729) with $\mathrm{Cu}$ source and $\theta-2 \theta$ geometry to analyse the crystallinity and phases of the grown materials. A nanonics multiview $1000^{\mathrm{TM}}$ SPM (Israel) system with a quartz optical fibre tip in intermittent contact mode was used to image the surface morphology of the catalyst layer. The AFM tip had a diameter of $20 \mathrm{~nm}$ and a spring constant of $40 \mathrm{~N} / \mathrm{m}$. Micro Raman measurements were carried out at room temperature on an alpha300 spectrometer (WITec Instruments) using a $532 \mathrm{~nm}$ laser as an excitation source and $100 \times 0.95 \mathrm{NA}$ objective. The spectral resolution of this Raman instrument is $1 \mathrm{~cm}^{-1}$ for a $532 \mathrm{~nm}$ laser line. 


\section{Results and discussion}

Figure 1(a) shows the FESEM image of the as-deposited $\mathrm{Ni}$ thin film on a silicon substrate. From the FESEM analysis, the average particle size was observed to be in the range of 120-150 $\mathrm{nm}$ (histogram in figure 1(a)). An additional AFM measurement was done to verify the morphology of the thin film before and after heat treatment. The particles were also resolved in the AFM image (figure $1 \mathrm{~b}$ ). The rms roughness of the as-grown thin film was determined to be $27.6 \mathrm{~nm}$. The XRD pattern (figure 1c) confirmed that the as-deposited thin film is pure $\mathrm{Ni}$.

Figure 2(a) and (b) shows the FESEM and figure 2(c) shows the AFM image of the $\mathrm{Ni}$ thin film on a silicon substrate after heat treatment at $850{ }^{\circ} \mathrm{C}$ in flowing hydrogen for $10 \mathrm{~min}$ under atmospheric pressure. After the heat treatment, the finer particles agglomerated to form bigger
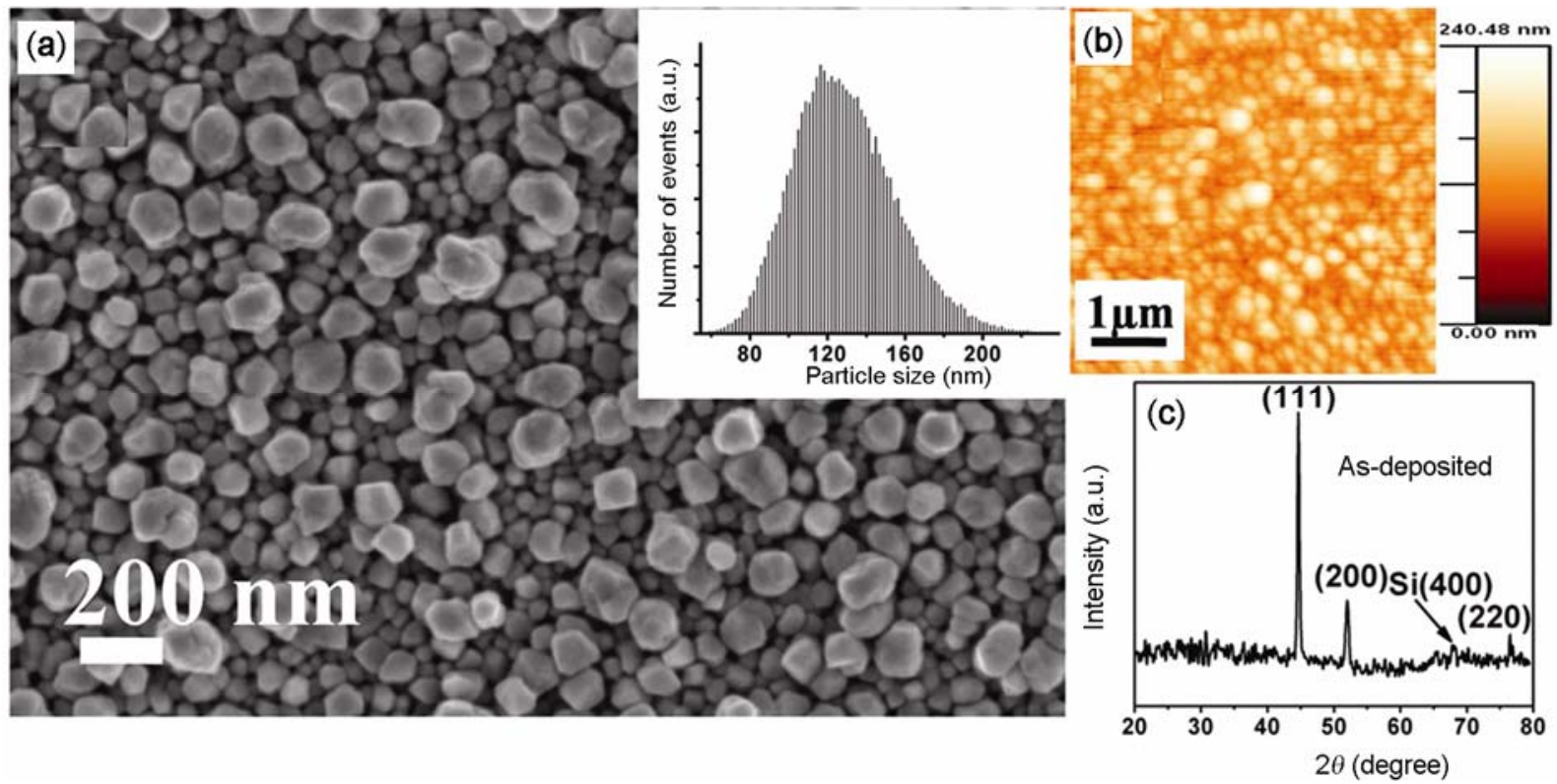

Figure 1. (a) SEM and (b) AFM image and (c) XRD pattern of the as-deposited dc sputtered Ni thin-film.

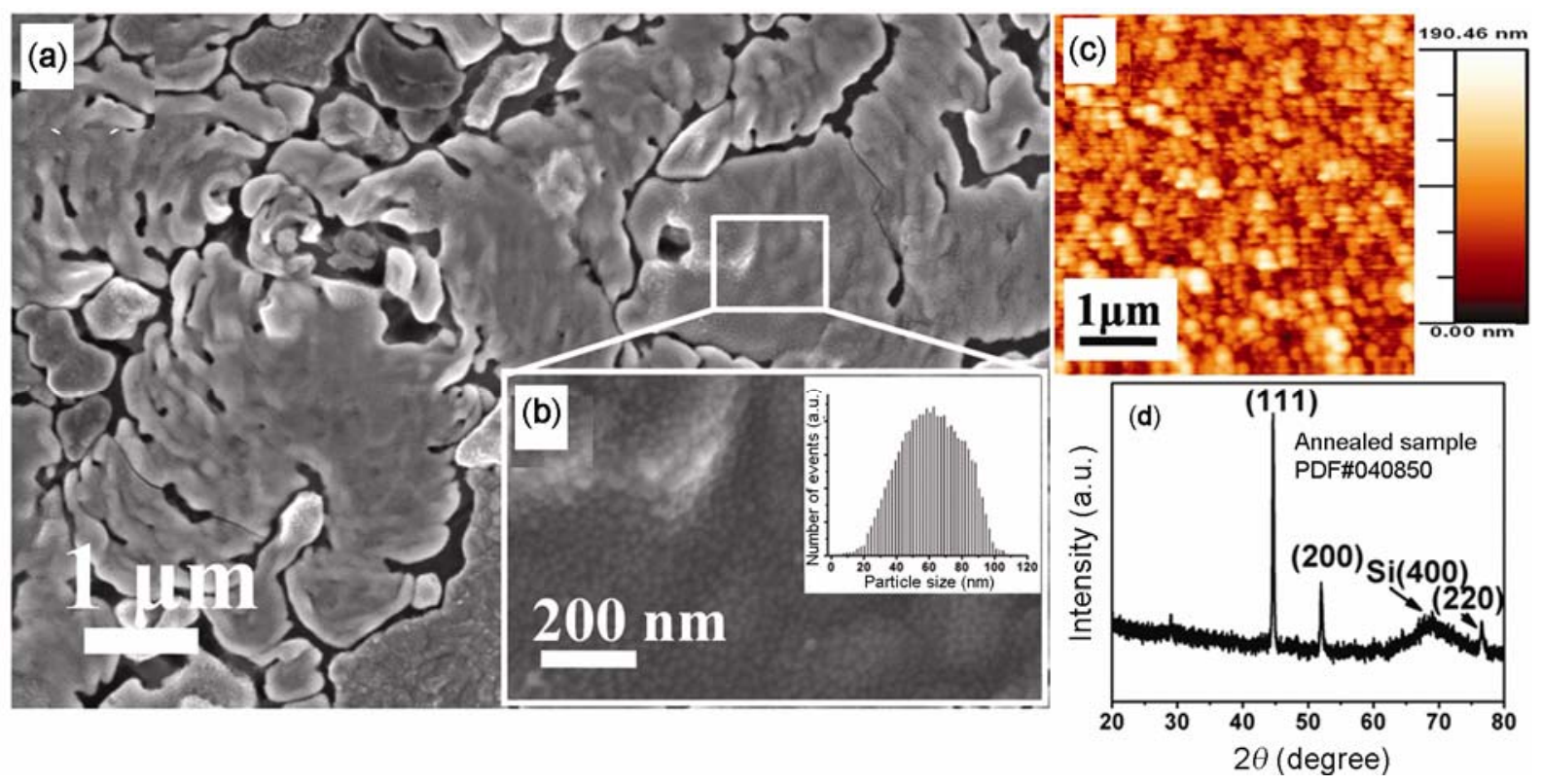

Figure 2. (a) FESEM and (b) AFM image and (c) of the $\mathrm{Ni}$ thin film annealed at $850{ }^{\circ} \mathrm{C}$ in hydrogen atmosphere before the growth of CNTs. 


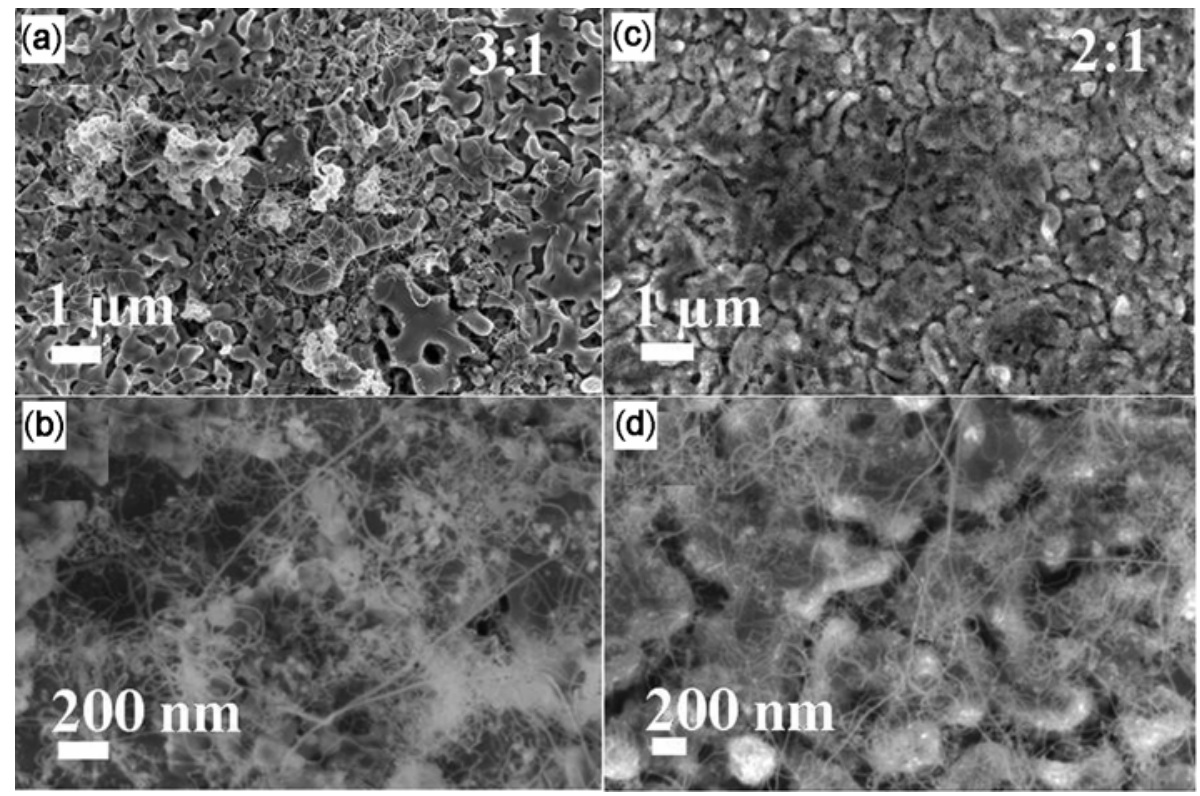

Figure 3. FESEM images showing the dependence of the flow ratio of propane to hydrogen during growth on the nature of carbon morphologies obtained. (a-b) Growth of CNTs when the flow ratio was 3:1 and (c-d) growth of CNTs when growth ratio was 2:1.

islands (figure 2a) with finer particles on top of the islands (figure $2 \mathrm{~b}$ ). The average particle size was in the range of $50-60 \mathrm{~nm}$ (inset histogram in figure $2 \mathrm{a}$ ). The rms roughness of the film after heat treatment was found to be $29 \mathrm{~nm}$. The XRD pattern (figure 2c) confirmed that the thin film of nickel retained its original phase after heat treatment in hydrogen. In both the XRD patterns (figures 1(c) and 2(c)), the substrate $\mathrm{Si}(400)$ peak was not so prominent because the $\mathrm{Si}$ substrate was an off-axis cut wafer. By in situ heat treatment, recrystallization in the film occurs with coalescence of finer particles to form coarser ones because of temperature dependencies of grain growth with constant annealing time (Tochitski and Chaplanov 1976). Hence, heat treatment leads to grain growth in the Ni thin film.

FESEM images of the carbon nanostructures grown by using sputtered Ni thin-film catalyst on the Si ( $\left.\begin{array}{lll}1 & 0 & 0\end{array}\right)$ substrate under different growth conditions (i.e. by varying the $\mathrm{C}_{3} \mathrm{H}_{8}$ and $\mathrm{H}_{2}$ ratio during growth) are shown in figures 3 and 4 . In the first batch of growth using a flow ratio to $3: 1\left(\mathrm{C}_{3} \mathrm{H}_{8}: \mathrm{H}_{2}\right)$, growth of CNTs is observed (figure 3(a and b)). Figure 3(b) is the higher magnification image of figure 3(a), and clearly shows as-grown CNTs. The CNTs appear to grow with high density in random directions. The average outer diameters of the as-grown CNTs were found to be in the range of 15$25 \mathrm{~nm}$. CNTs also formed when a flow ratio $\left(\mathrm{C}_{3} \mathrm{H}_{8}: \mathrm{H}_{2}\right)$ of 2:1 was used (figures 3(c and d)). CNTs are observed on the surface of the bigger islands of the catalyst (figure $3 b)$. These bigger islands with fine particles on their top surfaces are formed after the heat treatment of the catalyst film at high temperature in hydrogen atmosphere prior to the growth (figure 2a). The growth of the CNTs occurred from the fine particles during the subsequent steps of carbon diffusion and supersaturation. A similar growth morphology of the CNTs as in the previous case (i.e. $\mathrm{C}_{3} \mathrm{H}_{8}: \mathrm{H}_{2}$ ratio of $3: 1$ ) was observed. However, the growth density was higher compared to the previous batch (3: 1 flow ratio).

Figure 4( $a$ and $b)$ shows the low magnification and corresponding high magnification images of the as-grown CNFs, from the third batch of growth, when the flow ratio $\left(\mathrm{C}_{3} \mathrm{H}_{8}: \mathrm{H}_{2}\right.$ ratio $)$ was $2: 2$. The FESEM images suggest that the length and diameter of CNFs are greater than that of CNTs with increase of hydrogen concentration, whereas the number density of the CNFs is lower. Figure 4(a and b) taken from two different imaging areas of the same sample show different growth centres on the surface of the catalyst islands. The average growth length and external diameter of the CNFs are found to be in the range of $\sim 7-8 \mu \mathrm{m}$ and $\sim 120-130 \mathrm{~nm}$, respectively. More interestingly, the catalyst particles were observed at the tip of the as-grown CNFs (figure 4c), which indicates that the tip growth mechanism (Meyyappan et al 2003; Kumar and Ando 2010) is operative for the growth of the CNFs. With further decrease in hydrocarbon concentration $\left(\mathrm{C}_{3} \mathrm{H}_{8}: \mathrm{H}_{2}\right.$ ratio of $\left.1: 3\right)$ in the fourth batch of growth, flat two-dimensional carbon nanostructures (figure $4 \mathrm{~d}$ ) were observed. Figure $4(\mathrm{~d}-\mathrm{f})$ shows the FESEM images at an increasingly higher magnification. Flat sheets of carbon (figure $4 \mathrm{~d}$ ) and ribbon-like structures (figure 4f) were observed.

TEM has been conventionally used to characterize the interior structures of the as-grown carbon nanostructures. 


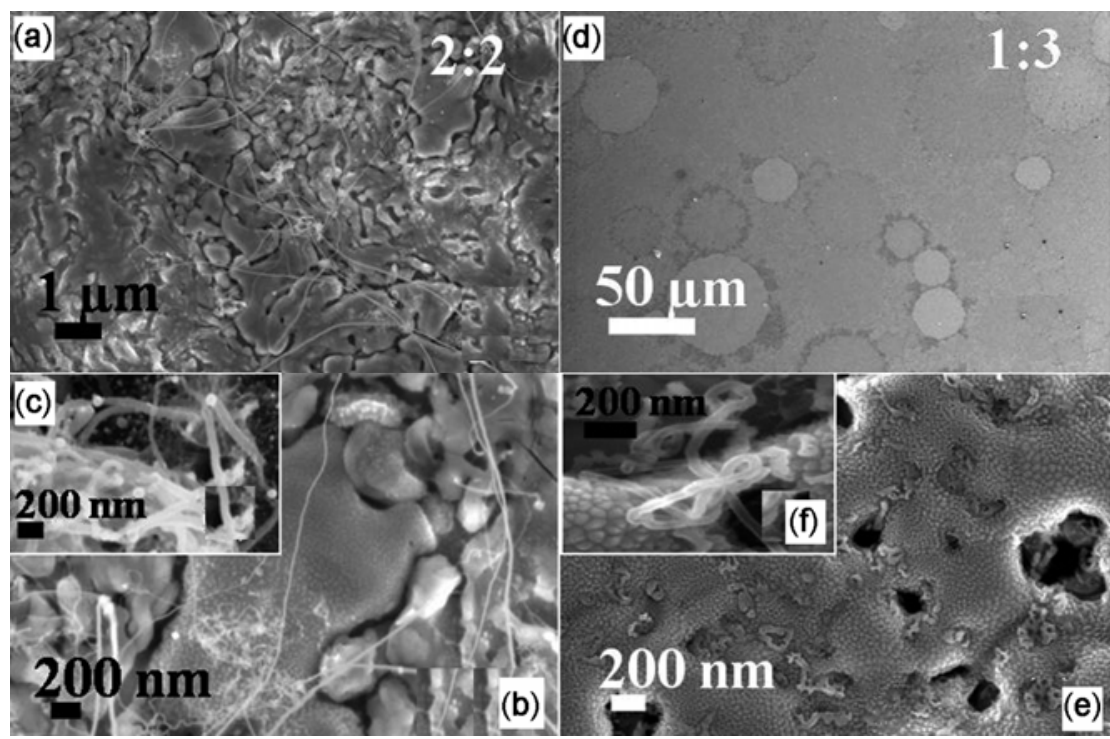

Figure 4. (a-c) FESEM images of the CNFs when the flow ratio was 2:2 and (d-f) growth of CNRs when flow ratio was 1:3.
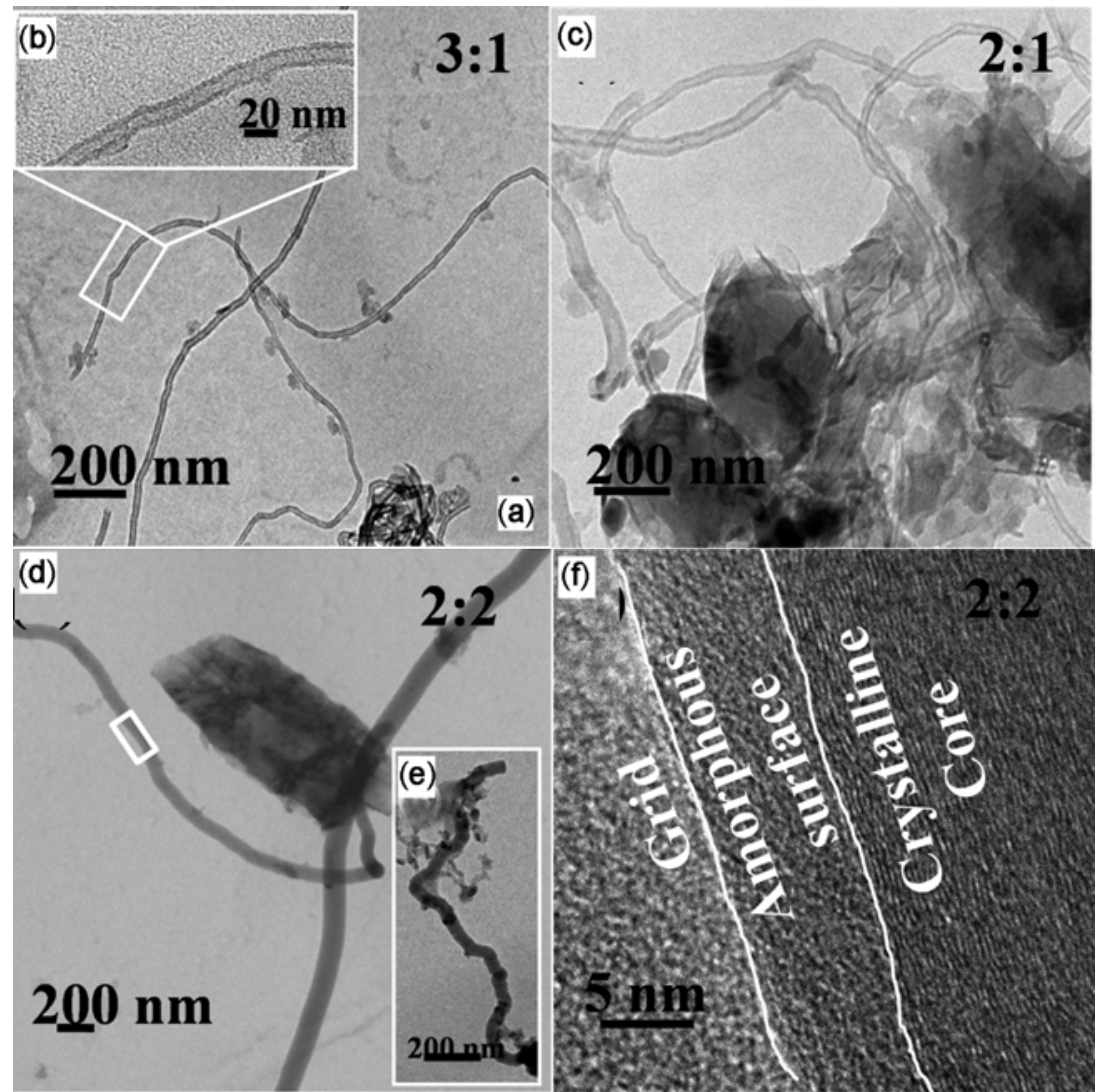

Figure 5. TEM characterization of carbon nanostructures as a function of propane: hydrogen flow ratio during growth using $\mathrm{Ni}$ as a catalyst. (a-b) CNTs formed with flow ratio of 3:1, (c) CNTs formed with flow ratio of $2: 1$, (d-e) CNFs formed with flow ratio of 2:2 and (f) HRTEM image of CNR exactly acquired from the rectangular mark portion in figure $5(\mathbf{d})$.

Figure 5(a) shows the TEM image of the as-grown CNTs grown using flow ratio of $3: 1\left(\mathrm{C}_{3} \mathrm{H}_{8}: \mathrm{H}_{2}\right.$ ratio). The average length and external diameter of these as-grown
CNTs were found to be in the range of $2-3 \mu \mathrm{m}$ and $15-$ $25 \mathrm{~nm}$, respectively. CNTs were also observed when the flow ratio was $2: 1\left(\mathrm{C}_{3} \mathrm{H}_{8}: \mathrm{H}_{2}\right.$ ratio). The tubular structure 


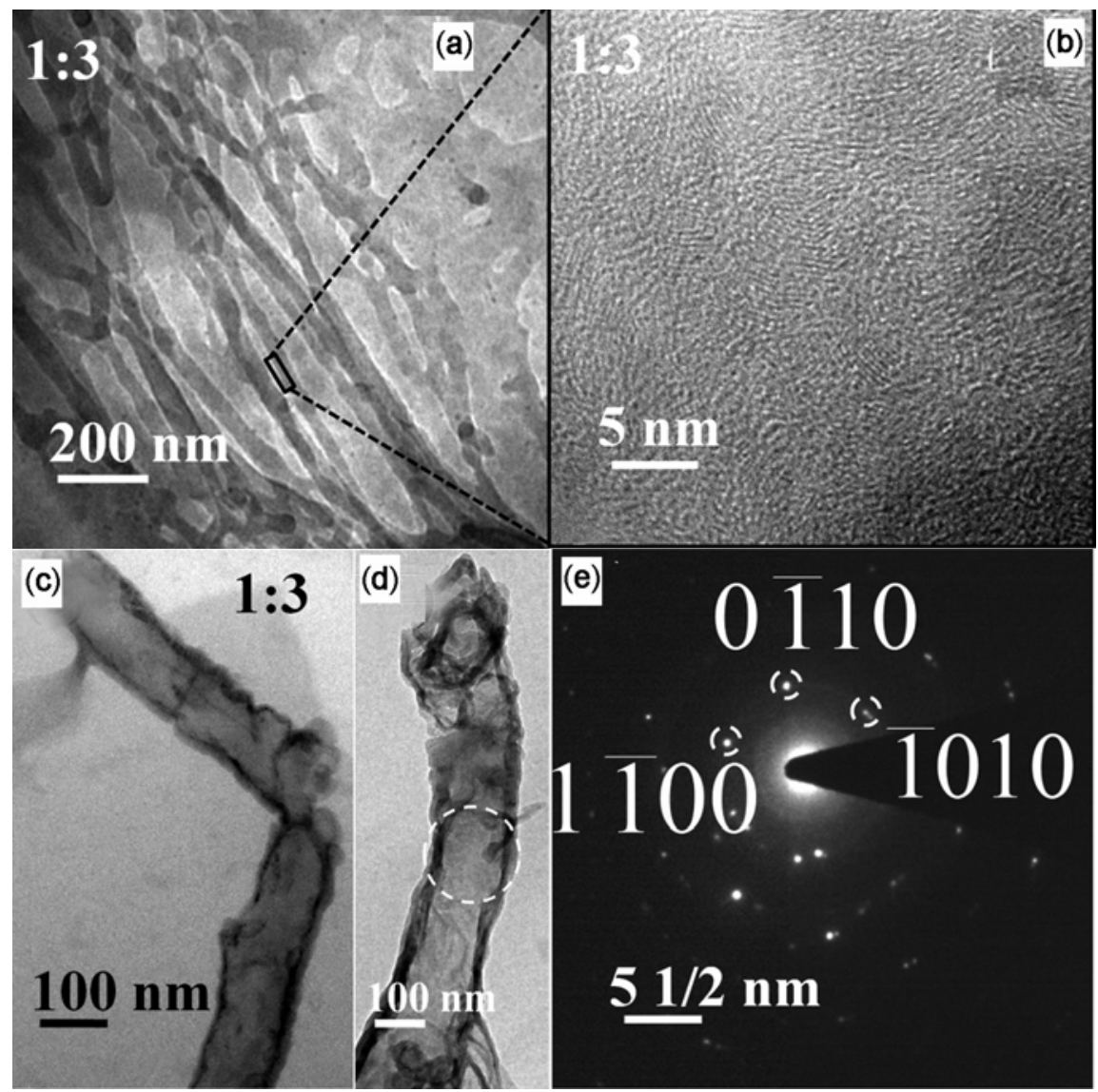

Figure 6. TEM images of CNRs formed with flow ratio of 1:3. (a) Low magnification image of the bunch of CNRs, (b) HRTEM image from a particular portion of the ribbon highlighted in figure 6(a), (c-d) two different imaging area of the same sample showing ribbons and (e) SEAD pattern of the ribbon obtained from the circular marked portion in figure $6(\mathbf{d})$.

was confirmed from the TEM image shown in figure 5(b). In this case, the average length was found to be 2-3 $\mu \mathrm{m}$ and the average outer diameter was found to be in the range of 25-30 $\mathrm{nm}$. This increase in diameter of the CNTs compared to the previous case $\left(3: 1 \quad \mathrm{C}_{3} \mathrm{H}_{8}: \mathrm{H}_{2}\right.$ growth case) can be linked to the increase in hydrogen concentration in the precursor gas. A similar phenomenon was previously observed by Xiong et al (2005). Based on their report, it is suggested that up to a certain concentration of hydrogen, hydrogen acts as a promoter of the catalyst. Subsequently, by changing the flow condition to $2: 2\left(\mathrm{C}_{3} \mathrm{H}_{8}: \mathrm{H}_{2}\right.$ ratio), CNFs were observed. The TEM images shown in figure $5(\mathrm{~d}$ and e) confirmed the formation of the CNFs with a solid inner structure. The HRTEM image (shown in figure 5f) was obtained exactly from the portion marked by a rectangle in figure $5(\mathrm{~d})$. The asformed CNFs show a crystalline graphitic core with the amorphous carbon sheath structure. The length and outer diameter of the CNFs were found approximately in the range of $\sim 5-7 \mu \mathrm{m}$ and $\sim 100-120 \mathrm{~nm}$, respectively. The measured values were close to the values obtained from FESEM. Finally, the last set of TEM images (figure 6) was acquired from the carbon nanostructures grown using the flow ratio $\left(\mathrm{C}_{3} \mathrm{H}_{8}: \mathrm{H}_{2}\right.$ ratio $)$ of $1: 3$. Ribbon-like structures exhibiting lengths of several micrometers and widths ranging from 90 to $150 \mathrm{~nm}$ (figure 6(a, c and d)) were observed. A lower magnification image (figure 6a) shows several ribbons in an agglomerated form on the carbon grid. The HRTEM image (figure 6b) obtained exactly form the rectangular mark in figure 6(a), confirmed the crystalline nature of the ribbon with built-in defects. It is interesting to note that some ribbons (from different imaging area of the same grid (figure 6(c) and 6(d)) revealed both flat inner regions as well as wavy defective boundaries. The edges of these ribbons (shown in figure 6(c) and 6(d)) were also relatively thick in comparison to the agglomerated CNRs (shown in figure 6a), which could be related to the stacking of several carbon layers.

The selected area diffraction pattern (SAED) was taken from the middle portion of the carbon nanoribbon marked by a circle in figure $6(d)$. The SAED pattern of the asgrown carbon nanoribbons matched with the single crystalline diffraction pattern of the $\left[\begin{array}{llll}0 & 0 & 0 & 2\end{array}\right]$ zone axis for hexagonal sets of planes of graphite (figure 6e). This SAED image confirmed that the graphitic crystallinity was high. 
The Raman spectra, considered as the characteristic of the vibration modes of the carbon nanomaterials, are shown in figure 7. The Raman band appearing in the $1500-1650 \mathrm{~cm}^{-1}$ region is denoted as the $G$ band and the Raman band appearing in the $1350-1450 \mathrm{~cm}^{-1}$ region is denoted as the $D$ band. The $G$ line corresponds to the $E_{2 \mathrm{~g}}$ mode, i.e. the stretching mode of the $\mathrm{C}-\mathrm{C}$ bond in graphite plane and demonstrates the presence of crystalline graphitic carbon (Dresselhaus et al 2008). The $D$-line originates from disorder in the $s p^{2}$-hybridized carbon and can be due to the presence of lattice defects in the graphitic walls. For all the as-grown carbon nanostructures, three common Raman active bands were observed in the high wave number region, i.e. around 1360,1580 and $2750 \mathrm{~cm}^{-1}$.

The relative intensity ratio of $D$ band to $G\left(I_{\mathrm{D}} / I_{\mathrm{G}}\right)$ band is an indicator of the graphitic layer stacking for the carbon nanostructure. For the $3: 1$ and $2: 1$ growth conditions, the $I_{\mathrm{D}} / I_{\mathrm{G}}$ ratios were found to be 0.42 and 0.75 , respectively. These values indicate that the graphitic crystallinity of the CNTs, when the flow ratio was $3: 1$, is better compared to those grown with $2: 1$ flow ratio. In the case of the $2: 1$ growth case, there also appears a shift in the $G$-band peak position approximately $25 \mathrm{~cm}^{-1}$

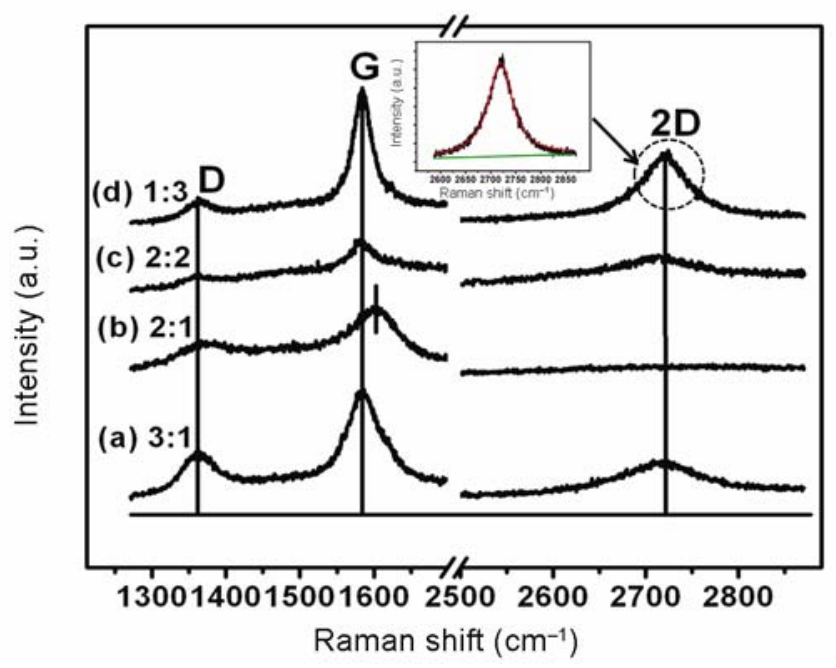

Figure 7. Raman spectra obtained from the as-grown carbon nanostructures as a function of propane: hydrogen flow ratio during growth. (a) CNTs: flow ratio of 3:1, (b) CNTs: flow ratio of 2:1, (c) CNFs: flow ratio of 2:2 and (d) CNRs-flow ratio of $1: 3$ with a insert shows the Lorenzian fitting of the $2 \mathrm{D}$ peak. towards a higher wave number. This increased $I_{\mathrm{D}} / I_{\mathrm{G}}$ value and positive shift in $G$-band peak position (in comparison to the $3: 1$ growth case) is expected due to the presence of more defect sites (Choi et al 2002). The value of the $I_{\mathrm{D}} / I_{\mathrm{G}}$ ratio in case of the CNFs (i.e. at $2: 2$ ) was found to be 0.43 . The value of the $I_{\mathrm{D}} / I_{\mathrm{G}}$ was observed to be very low, i.e. $0 \cdot 15$, for the flat two-dimensional carbon nanoribbon-like structures. In case of the carbon ribbon-like structures, the ratio of the $I_{\mathrm{G}} / I_{2 \mathrm{D}}$ is considered as a reference for the number of stacked layers, whereas in case of the CNTs and CNFs this value is of less interest. In this case $\left(\mathrm{C}_{3} \mathrm{H}_{8}: \mathrm{H}_{2}\right.$ ratio $\left.1: 3\right)$, the value of the $I_{\mathrm{G}} / I_{2 \mathrm{D}}$ was found to be 0.4 and the $2 \mathrm{D}$ peak shape is Lorenzian (as shown in the insert in figure 6), which indicates the formation of few layered graphene nanoribbon structure (Gupta et al 2006; Graf et al 2007; Das et al 2008; Bischoff et al 2011). The above data are summarized in table 1.

From the above observations, growth of CNTs, CNFs and CNRs like structures was observed by varying the $\mathrm{C}_{3} \mathrm{H}_{8}: \mathrm{H}_{2}$ mixture ratio during growth. An increased higher-order hydrogen concentration corresponds to thicker, longer and less curved CNF and wider twodimensional CNR-like structures due to the reduced reaction rate. However, a lower hydrogen concentration produces thinner diameter, shorter length CNTs with a high density because of the faster reaction rate and the catalyst's partial surface deactivation. The increase in the hydrogen concentration prevents the catalyst deactivation at high temperature. The current experimental results agree with previous reports of growth of CNTs and CNFs under different precursor concentration (Rostrup-Nielsen 1974; Makris et al 2005; Crossley et al 2010). Comparisons with previous studies demonstrate that the presence of hydrogen in the reaction has modified the carbon diffusion pathways. It is revealed that hydrogen has the following function during growth: first, chemisorbed hydrogen prevents graphitic over layer formation; second, hydrogen helps in etching out the $s p^{2}$ hydrocarbons during growth, which enhances the quality of the carbon nanostructures (Xu et al 2006), and lastly, hydrogen adsorbed on the catalyst surface creates surface imbalances by breaking bond co-ordinations by inducing surface atom mobility, which leads to surface reconstruction and grain growth on the thin film surface. The newly

Table 1. Raman features of the as-grown carbon nanostructures in the range between 1200 and $2800 \mathrm{~cm}^{-1}$ are listed.

\begin{tabular}{lccccc}
\hline $\begin{array}{l}\mathrm{C}_{3} \mathrm{H}_{8}: \mathrm{H}_{2} \\
\text { flow ratio }\end{array}$ & $\begin{array}{c}\text { D peak position } \\
\left(\mathrm{cm}^{-1}\right)\end{array}$ & $\begin{array}{c}\text { G peak position } \\
\left(\mathrm{cm}^{-1}\right)\end{array}$ & $\begin{array}{c}\text { 2D peak position } \\
\left(\mathrm{cm}^{-1}\right)\end{array}$ & $I_{\mathrm{D}} / I_{\mathrm{G}}$ ratio & $I_{\mathrm{G}} / I_{2 \mathrm{D}}$ \\
\hline $3: 1$ & $1362 \cdot 2$ & $1584 \cdot 01$ & $2717 \cdot 7$ & $0 \cdot 42$ & $0 \cdot 5$ \\
$2: 1$ & $1362 \cdot 4$ & $1609 \cdot 8$ & $2719 \cdot 2$ & $0 \cdot 75$ & $1 \cdot 26$ \\
$2: 2$ & $1362 \cdot 4$ & $1584 \cdot 5$ & $2721 \cdot 1$ & $0 \cdot 43$ & $0 \cdot 55$ \\
$1: 3$ & $1362 \cdot 5$ & $1584 \cdot 1$ & $2714 \cdot 8$ & $0 \cdot 15$ & $0 \cdot 42$ \\
\hline
\end{tabular}


reconstructed surface is a preferable growing site for carbon nanofibre formation under moderate hydrocarbon concentrations (Chen et al 2006) and for flat carbon nanoribbon under very low hydrocarbon flow condition during growth.

\section{Conclusions}

The most significant result of the present work is that the growth of CNTs, CNFs and CNR-like structures is strongly dependent on the hydrogen concentration during growth. Electron microscopy imaging confirmed this variation in grown structures. The electron diffraction suggests the formation of highly crystalline graphitic carbon nanoribbon-like structures at low propane and high hydrogen flow ratio. The present work demonstrates that control over the reaction kinetics by controlling the flow ratio of propane to hydrogen is the primary requirement for the controlled growth of CNTs, CNFs or CNRs like structure. The reaction kinetics directly affect the surface diffusion of carbon and decomposition of hydrocarbons on the catalyst surface during growth. Hence, the flow ratio of propane to hydrogen inside the reaction chamber during growth is one of the key process parameters for the control of growth.

\section{Acknowledgements}

We thank Mr Dilip Chakrabarty from the Arun Sarin Electronics Materials Research Laboratory for helping in sputter deposition. Special thanks to Prof. R Mitra for allowing us to use the Arun Sarin Electronics Materials Research Laboratory in the Department of Metallurgical and Materials Eng., Indian Institute of Technology Kharagpur.

\section{References}

Baker R T K 1989 Carbon 27315

Bartholomew C H 1982 Catal. Rev. - Sci. Eng. 2467

Benito A M, Maniette Y, Munoza E and Martinez M T 1998 Carbon 36681

Bianchini E C and Lund C R F 1989 J. Catal. 117445

Bischoff D, Güttinger J, Dröscher S, Ihn T, Ensslin K and Stampfer C 2011 J. Appl. Phys. 109073710

Chae S J, Güneş F, Kim K K, Kim E S, Han G H, Kim S M, Shin H-J, Yoon S-M, Choi J-Y, Park M H, Yang C W, Pribat D and Lee Y H 2009 Adv. Mater. 212328

Cherukuri L D, Yuan G and Keane M A 2004 Top Catal. 29 119
Chen C-M, Dai Y-M, Huang J G and Jehng J-M 2006 Carbon 441808

Choi S, Park K H, Lee S and Koh K H 2002 J. Appl. Phys. 92 4007

Crossley B L, Kossler M, Coutu R A, Starman L A and Collins P J 2010 J. Nanophoton. 4049501

Das A, Chakraborty B and Sood A K 2008 Bull. Mater. Sci. 31 579

Dresselhaus M S, Dresselhaus G and Hofmann M 2008 Phil. Trans. R. Soc. A366 231

Graf D, Molitor F, Ensslin K, Stampfer C, Jungen A, Hierold C and Wirtz L 2007 Nano Lett. 7238

Gupta A, Chen G, Joshi P, Tadigadapa S and Eklund P C 2006 Raman Nano Lett. 62667

Hong G, Chen Y, Li P and Zhang J 2012 Carbon 502067

Huang S, Cai Q, Chen J, Qian Y and Zhang L 2009 J. Am. Chem. Soc. 1312094

Huang W, Zhang X-B, Tu J, Kong F, Ning Y, Xuab J and Tendeloo G V 2002 Phys. Chem. Chem. Phys. 45325

Jablonski G A and Sacco J A 1992 Carbon 3087

Jung M, Eun K Y, Lee J-K, Baik Y-J, Lee K-R and Park J W 2001 Diamond Relat. Mater. 101235

Kato T and Hatakeyama R 2012 Nat. Nanotechnol. 7651

Kumar M and Ando Y 2010 J. Nanosci. Nanotechnol. 103739

Makris T D, Giorgi L, Giorgi R, Lisi N and Salernitano E 2005 Diamond Relat. Mater. 14815

Meyyappan M, Delzeit L, Cassell A and Hash D 2003 Plasma Sour. Sci. Technol. 12205

Nessim G D, Seita M, Plata De L, O'Brien K P, Hart A J, Meshot E R, Reddy C M, Gschwend P M and Thompson C V 2011 Carbon 49804

Park C and Keane M A 2001a Catal. Commun. 2171

Park C and Keane M A 2001b Langmuir 178386

Park C and Keane M A 2002 J. Colloid. Interf. Sci. 25037

Park C and Keane M A 2004 J. Catal. 221386

Pollard A J, Nair R R, Sabki S N, Staddon C R, Perdigao L M A, Hsu C H, Garfitt J M, Gangopadhyay S, Gleeson H F, Geim A K and Beton P H 2009 J. Phys. Chem. C38 16565

Ren W, Li F, Bai S and Cheng H-M 2006 J. Nanosci. Nanotechnol. 61339

Rostrup-Nielsen J R 1974 J. Catal. 33184

Snoeck J W, Froment G F and Fowles M 1997 J. Catal. 169 240

Tochitski E I and Chaplanov A M 1976 Thin Solid Films 32213

Umair A and Raza H 2012 Nanoscale Res. Lett. 7437

Wang D, Tian H, Yang Y, Xie D, Ren T-L and Zhang Y 2013 Nat. Sci. Rep. 31

Xiong Y G, Suda Y, Wang D Z, Huang Y J and Ren Z F 2005 Nanotechnology 16532

Xu F, Liu X and Tse S D 2006 Carbon 44570

Yu D, Zhang Q and Dai L 2010 J. Am. Chem. Soc. 1325127

Yu Q, Lian J, Siriponglert S, Li H, Chen Y P and Pei S-S 2008 Appl. Phys. Lett. 93113103

Yuan D, Ding L, Chu H, Feng Y, McNicholas T P and Liu J 2008 Nano Lett. 82576 